\title{
Tensile properties of rat anterior cruciate ligament in collagen induced arthritis
}

\author{
K Nawata, M Enokida, D Yamasaki, T Minamizaki, H Hagino, Y Morio, R Teshima
}

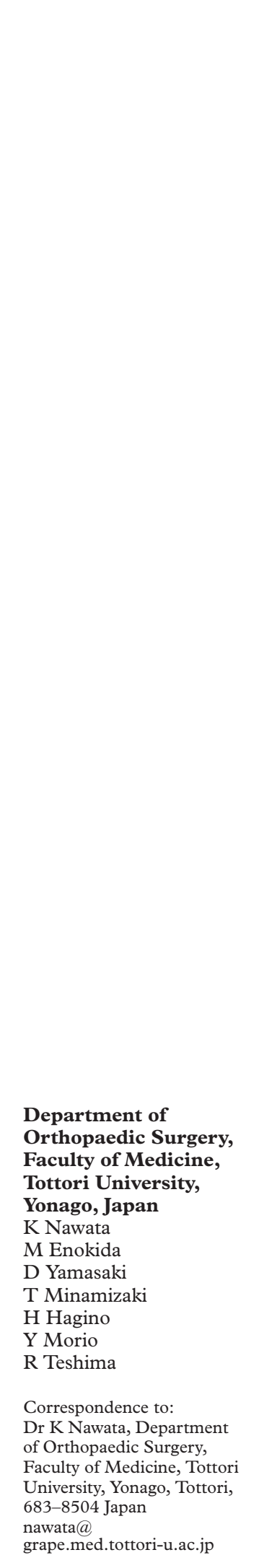

Accepted 5 September 2000

\begin{abstract}
Objectives-To investigate the effects of collagen induced arthritis (CIA) on the tensile properties of rat anterior cruciate ligament (ACL).

Methods-The tensile strength, bone mineral density (BMD), and histology of ACL units from rats with CIA were investigated. Results-The tensile strength of the ACL unit was significantly lower in the rats with CIA at 10 weeks after immunisation (ultimate failure load, $74.9 \%$ of the con(ultimate failure load, $74.9 \%$ of the control; stiffness, $62.0 \%$ of the control). The
major mode of failure was femoral avulmajor mode of failure was femoral avulsion, and the BMD was significantly lower nation of the ligament insertion in rats with CIA showed resorption of the cortical bone beneath the ACL insertion and an enlarged mineralised fibrocartilage zone. Conclusions-These findings indicate that the decrease in tensile strength of ACL units correlated with histological changes in the ligament-bone attachment, such as bone resorption beneath the ligament insertion site and an enlargement of the mineralised fibrocartilage zone.

(Ann Rheum Dis 2001;60:395-398)
\end{abstract}

Rheumatoid arthritis (RA) is a chronic systemic disease. The knee joints of patients with RA are commonly affected by ligamentous axity. ${ }^{1-5}$ Although the instability is partly due to destruction of cartilage and bone in severely affected knees, knee stability is mainly provided by the ligaments, which are important components of the mechanical functioning of the knee. It is also known that laxity or instability may contribute to the development an progression of degeneration and attrition of the articular cartilage. ${ }^{6-8}$ However, little is known about changes in the tensile properties of ligaments in RA.

Collagen induced arthritis (CIA) is a well known disease model for RA. CIA resembles RA in a number of pathological, histological, and immunological aspects. ${ }^{9-11}$ Features of CIA include chronic synovitis, including inflammatory cell infiltration, pannus formation, destruction of cartilage, and bone erosion.

In this study we aimed at clarifying the changes in tensile properties and histology occurring in the anterior cruciate ligament (ACL) of rats with CIA.

\section{Materials and methods}

ANIMALS

Female Sprague-Dawley rats, 4 weeks of age, were obtained from Shimizu Laboratory Supply Co (Kyoto, Japan) and acclimatised for four weeks under standard laboratory conditions. All rats were 8 weeks old at the beginning of the study. During the experimental period, tap water and commercially available food (CE-2, CLEA Japan Inc, Tokyo; calcium content $1.18 \mathrm{~g} / 100 \mathrm{~g}$; phosphorus content $1.09 \mathrm{~g} / 100 \mathrm{~g}$; vitamin $\mathrm{D}_{3}$ content 250 $10 \mathrm{U} / 100 \mathrm{~g})$ were given freely. The lighting duration in the breeding room was 12 hours ( 7 $24^{\circ} \mathrm{C}$ The experiment was approved by the Committee of Laboratory Animals, Faculty of Medicine, Tottori University.

EXPERIMENTAL DESIGN

Twenty rats were categorised by body weigh nto two groups of 10 animals each. In the first (SD 9.95) arthritis was induced. The other group (conrol group), weighing $137.8(2.76) \mathrm{g}$, served as the age matched controls. There was no ignificant difference in body weight between the groups $(p=0.533)$. The clinical signs of arthritis and bone mineral density were evaluated by the same person for each rat. Rats were killed 10 weeks after the start of the experiment. The fem me The femur-ACL-tibia complex right knee of each rat was used for mechanical testing. The ACL from the left knee was examined histologically.

NDUCTION OF CIA

CIA was induced by established methods as previously described. ${ }^{9}$ Briefly, rats were injected intradermally around the root of the tail with $0.5 \mathrm{mg}$ bovine type II collagen (Cosmo Bio Co, Tokyo, Japan) dissolved in $0.5 \mathrm{ml}$ ncomplete Freund's adjuvant (Difco). Seven days later, the rats were given a booster by the same method. A clinical evaluation of arthritis was performed by measuring the thickness of the hind foot using calipers every two weeks after immunisation.

BONE DENSITOMETRY

An in vivo bone mineral measurement was performed at eight weeks after immunisation by peripheral quantitative computed tomography (pQCT; XCT-960, Norland-Stratec). The rats were anaesthetised with $50 \mathrm{mg} / \mathrm{kg}$ body weight of ketamine hydrochloride and 10 g/kg bylazine intraperito(me $2 \mathrm{~mm}$ apart (metaphysis) from the epiphysial line. A 0.30 $\mathrm{mm}$ voxel was used. A threshold for cortical bone of 0.93 and for trabecular bone of 0.63 was selected to establish a tomographic limit between the cortical and trabecular bone regions. The coefficient of variation for the measurement of bone density by pQCT was $1 \%$. 
TENSILE FAILURE TEST

All specimens were dissected just before testing. The femur-ACL-tibia preparation was carried out by adapting an established method. ${ }^{12}$ The dissected specimens were mounted at approximately 80 degrees of knee flexion on a test fixture, which was designed so flexion on a test fixture, which was designed so
that the only relative motion that could occur that the only relative motion that could occur
between the tibia and femur was linear between the tibia and femur was linear
displacement nearly parallel to the axis of the ligament. A conventional tensile tester (Autograph AGS-H; Shimadzu, Kyoto, Japan) was The specin testing to failure at an elongation rate of $10 \%$ of the initial ligament length per second.

Histological EVALUATION

The left knees for histological examination were removed immediately after death, and the extra-articular soft tissues were dissected and fixed in $10 \%$ buffered formalin solution, decalcified, and in paraffin blocks. For each block, $10 \mu \mathrm{m}$ sections were made through the femoral insertion, ACL, and tibial insertion and stained with haematoxylin and eosin for light microscopy.

STATISTICAL ANALYSIS

Calculations were performed with Stat-View $4.02 \mathrm{~J}$ on a Macintosh. The onset time of arthritis was analysed with the repeated measure analysis of variance and Dunn tests. ure analysis of variance and Dunn tests.
Student's $t$ test was used to compare body Student's $t$ test was used to compare body weights, the bone mineral density, and the
mechanical properties between groups. The level of significance for all analyses was $p<0.05$.

\section{Results}

CLINICAL COURSE OF ARTHRITIS

Arthritis occurred in the CIA group at two weeks after the primary immunisation, and hind foot swelling reached a plateau after four weeks of follow up (fig 1).

BONE DENSITOMETRY

Values of bone mineral density (BMD) in the CIA group were significantly lower than those in the control group at eight weeks after immunisation $(\mathrm{p}<0.01)$. Total $\mathrm{BMD}$ was $74.6 \%$, trabecular BMD $60.7 \%$, and cortical BMD $83.0 \%$ of the controls (table 1 ).

TENSILE PROPERTIES

The major mode of failure was femoral avulsion in the femur-ACL-tibia specimens of both groups (six of 10 specimens in the control

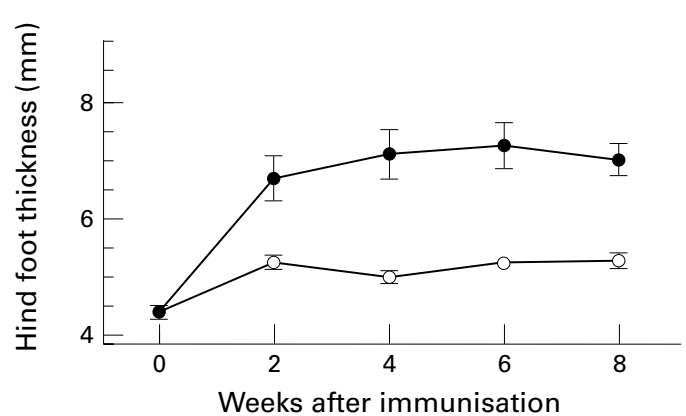

Figure 1 Changes in hind foot oedema. Each value is the mean and SEM. Open symbols represent control rats; closed
symbols represent rats with collagen induced arthritis. Table 1 Bone mineral density (BMD) at eight weeks after
immunisation. Values are given as the mean (SD)

\begin{tabular}{lll}
\hline & Control & CIAt \\
\hline Total BMD $\left(\mathrm{mg} / \mathrm{cm}^{3}\right)$ & $583.3(58.0)$ & $434.9(69.6)^{\star}$ \\
Trabecular BMD & $402.1(50.4)$ & $244.2(31.0)^{\star}$ \\
Cortical BMD & $716.0(46.4)$ & $594.3(102.8)^{\star}$ \\
\hline
\end{tabular}

Significantly different from control (Student's $t$ test, $\mathrm{p}<0.01$ ). 'Significantly different from control (Student's $t$ test, $p<0.01$ )
-CIA = collagen induced arthritis.

Table 2 Tensile properties of the anterior cruciate ligamen unit. Values are given as the mean $(S D)$

\begin{tabular}{lll}
\hline & Control & CIAt \\
\hline Ultimate failure load $(\mathrm{N})$ & $26.7(8.6)$ & $20.0(4.5)^{\star}$ \\
Stiffness $(\mathrm{N} / \mathrm{mm})$ & $41.3(19.3)$ & $25.6(10.1)^{\star}$ \\
Energy to failure $\left(\times 10^{-2} \mathrm{Nmm}\right)$ & $4.0(3.8)$ & $1.7(0.7)$ \\
\hline
\end{tabular}
*Significantly different from control (Student's $t$ test, $\mathrm{p}<0.05$ ).

group and eight of 10 in the CIA group). The femur-ACL-tibia complex had a significantly ower ultimate failure load and stiffness in the CIA group than in the control group $(\mathrm{p}<0.05)$. Table 2 summarises the mechanical testing data.

HSTOLOGICAL FINDINGS

In the CIA group, subsynovial resorption of bone around the bone-pannus junction was seen at the peripheral margins of the ligament insertion site. Vascular foramina in the cortical bone beneath the ACL insertion were enlarged with inflammatory cell infiltration. The whe number of chondrocytes increased in the minralised fibrocartilage zone, which was enlarged. No histological changes were seen in the ligament substance among rats with CIA compared with the control rats (fig 2).

\section{Discussion}

Several clinical studies have focused on changes in knee laxity in patients with RA using quantitative measurements. ${ }^{235}$ Wada et al reported that anteroposterior knee laxity increased in RA knees, and that a high rate of morphological damage to the cruciate ligamorphological damage to the cruciate liga-
ments was seen. ${ }^{5}$ However, the mechanism of ments was seen. ${ }^{5}$ However, the mechanism
these laxity changes has not been clarified.

This is the first study, to our knowledge, to clarify the effects of CIA on the tensile and histological properties of rat ACL. Our findings show that the tensile strength of the ACL was significantly lower in rats with CIA (ultimate failure load, $74.9 \%$ of the control; stiffness, failure load, $74.9 \%$ of the control; stiffness,
$62.0 \%$ of the control). The major mode of fail$62.0 \%$ of the control). The major mode of fail-
ure was femoral avulsion, and the BMD was significantly lower in the rats with CIA. A histological examination of the ligament insertion in rats with CIA showed resorption of the cortical bone beneath the ACL insertion and an enlarged mineralised fibrocartilage zone. These findings suggest that structural and mechanical changes occur in the ligament insertion of the ACL in CIA.

Periarticular osteoporosis is a common clinical feature of RA. Histomorphometric studies in the periarticular bone of patients with RA showed the presence of increased bone resorption through osteoclast activation. ${ }^{13}{ }^{14}$ Several studies have also shown bone loss in arthritis 

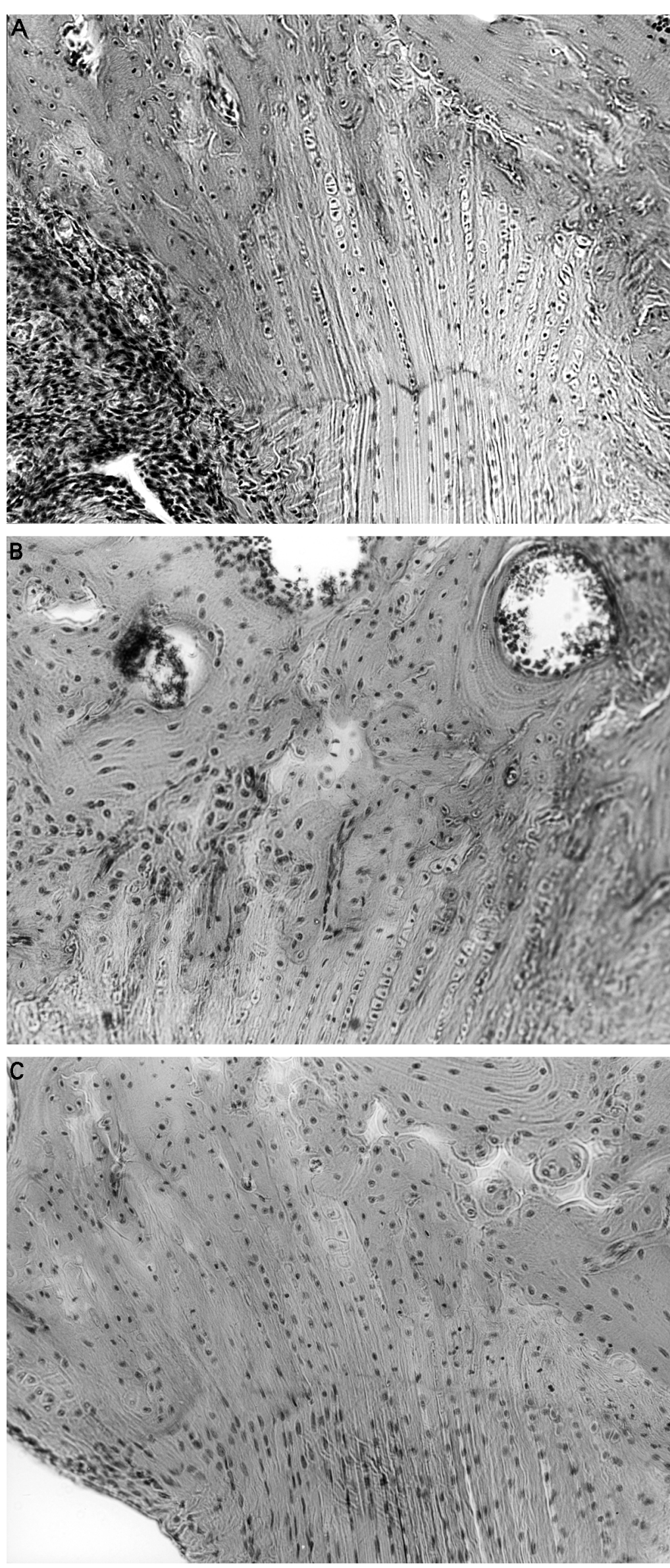

Figure 2 Light micrographs of femoral insertion sites of the anterior cruciate ligament
$(A C L)$ (haematoxylin and eosin). $(A)$ Group with collagen induced arthritis $(\times 100)$. Photomicrograph shows bone resorption around the bone-pannus at the peripheral margins of the ligament insertion site and the enlarged mineralised fibrocartilage zone. (B) Enlarged vascular foramina with inflammatory cell infiltration in
insertion is shown $(\times 200)$. (C) Control group $(\times 100)$. experimental models. ${ }^{15-19}$ In this study the cortical BMD was significantly lower in rats with CIA, and enlarged vascular foramina in the cortical bone beneath the ACL insertion and subsynovial resorption of bone at the periphel marins of the ligament insertion site were seen.

Dolgo-Saburoff in 1929, using a cat patellartendon insertion into the tibia, described fou zones: tendon, fibrocartilage, mineralised fibrocartilage, and bone. ${ }^{20}$ Cooper and Misor studied dog ligament insertions. They proposed that the fibrocartilage zone and the mineralised fibrocartilage zone might afford a gradual transmission of the tensile force between ligament and bone, and act as a growth zone for ligament and underlying bone. ${ }^{21}$ In this study the mineralised fibrocartilage zone was enlarged with an increased number of chondrocytes in rats with CIA. It was considered that cyces in rats with CIA. It was considered that reduced functioning of the growth zone in CIA. Consequently, an enlargement of the mineralised fibrocartilage zone would affect the viscoelastic properties of the ligament insertion.

The decreased mechanical strength of the bone-ACL-bone complex from rats with CIA is considered to be due to these histological changes at the ligament-bone insertion site, in bone, the fibrocartilage zone, or both. The changes in the relation between load and ligament elongation in CIA were shown as a decrease in ligament stiffness. These results indicate that the projected in vivo functional capacity of the ligament unit would be altered by CIA.

This study had several limitations. Firstly, we used young rats and therefore the structures of the ligament insertions are different from those of skeletally mature humans. We selected young rats because they are usually used in experimental studies on arthritis, and an arthritis model of the skeletally mature rat has mon mode of failure was a femoral avulsion in his study. Noyes and Grood reported that the major mode of ACL failure in tensile failure tests was ligament disruption in young adult humans and avulsion of the bone beneath the ligament insertion site in older humans ${ }^{22}$ Noyes et al also reported that in adult rhesus monkeys the major mode of ACL failure changed from a predominance of tibial avulsion at slow strain rate to ligament disruption at a fast rate. ${ }^{12}$ On the other hand, Danto and Woo reported that in skeletally mature rabbits, strain rate had no effect on the mode of failure, and most ACL units failed at the insertion site ${ }^{23}$ This variability in the mode of failure may be due to multiple factors, such as animal species, age, and testing procedures used. Finally, there were no histological changes in the ACL substance of rats with CIA despite their decreased stiffness. A biochemical analysis of the collagen metabolism in ACL would be needed to clarify this observation. ${ }^{24}$

In conclusion, our findings showed that the tensile strength of the ACL unit was decreased in CIA. The effect of CIA on the ACL unit 
depended on the histological characteristics of the ligament-bone attachment, such as bone resorption beneath the ligament insertion site and an enlargement of the mineralised fibrocartilage zone.

This work was partly supported by a grant from the Japanese
Ministry of Education (No 09877289).

1 Coomes EN. Lateral instability of the knee following polyar1962;21:378-87. Kolastad K, Sahlstedt B, Wigren A. Extension defect and
lateral instability in degenerative disease of the knee. Acta lateral instability in degenerative disease of the Knee. Acta
Orthop Scand 1980;51:667-72. Wright V. Measurement of out Rand T, Breitenseher M, Haller J, Graninger W, Imhof H, Radiologe 1996;36:617-23. Wada M, Imura S, Baba H, Shimada S. Knee laxity in
patients with osteoarthritis and rheumatoid arthritis. Br J

6 Pond MJ, Nuki G. Experimentally-induced osteoarthritis in the dog. Ann Rheum Dis 1973;32:387-8.

transection model of osteoarthritis. In cruciate ligament Diamond HS, eds. CRC handbook of animal models for the rheumatic diseases. Vol 2. Boca Raton (FL): CRC Press,
1988:57-82. Woo SL-Y, Lewis JL, Suh J-K, Engebretsen L. Acute injury to ligament and meniscus as inducers of osteoarthritis. In Kuettner KE, Goldberg VM, eds. Osteoarthritic disorders
Rosemont (IL): American Academy of Orthopaedic Surgeons, 1995:185-96. Trentham DE, Townes AS, Kang AH. Autoimmunity to
type II collagen: an experimental model of arthritis. J Exp Med 1977;146:857-68.
Courtenay JS, Dallman MJ, Dayan AD, Martin A Courtenay JS, Dallman MJ, Dayan AD, Martin
Mosedale B. Immunisation against heterologous type II
collagen induces arthritis in mice. Nature 1980;283: collagen induces arthritis in mice. Nature 1980;283:
$666-8$.

11 Stuart JM, Townes AS, Kang AH. Nature and specificity of the immune response to collagen in type II collagen-
induced arthritis in mice. J Clin Invest 1982;69:673-83.
12 Noyes FR, DeLucas JL, Torvic PJ. Biomechanics of anterio ity and mechanisms of failure in primates. J Bone Joint Surs Am 1974;56:236-53. Havdrup T, Hulth A, Telhag $H$. The subchondral bone in
osteoarthritis and rheumatoid arthritis of the knee. Acta Osteoarthritis and rheumatoid

14 Shimizu S, Shionzawa S, Shinozawa K, Imura S, Fuita T. Quantitative histologic studies on the pathogenesis of pe articular osteoporosis in rheumatoid arthritis. Arthriti
Rheum 1985;28:25-31. 15 Minne HW, Pfeilschifter J, Scharla S, Mutschelknauss S, Schwarz A, Krempien B, et al. Inflammation-mediate osteopenia in the rat: a new animal model for pathologica 6 Pfeilschifter J W W Wuster C Vology M, Enderes B. Zie Minne HW. Inflammation-mediated osteopenia (IMO) during acute inflammation in rats is due to a transient inhbition of bone formation. Calcif Tissue Int 1987,41:321$\mathrm{D}$ metabolism in rats with adjuvant-induced arthritis.

Bone Miner Res 1990;5:905-13.
Bonnet J, Zerath E, Picaud N, Lesur C, Mattio A, Tordiman polyarthritic osteopenia in rat: evidence for formation defect. J Bone Miner Res 1993;8:659-68. 19 Hanyu T, Chotanaphut K, Arie K, Tanaka T, Takahas rats with type II collagen-induced arthritis. Bone 1999;24: 485-90.
Dolgo-Saburoff B. Uber ursprung und insertion der
skelettmuskeln. Anat Anz 1929;68:30-87.

1 Cooper RR, Misor S. Tendon and ligament insertion. A light and electron microscopic study. J Bone Joint Surg Am
1970;52:1-20.

Noyes FR, Grood ES. The strength of the anterior cruciate species-related changes. J Bone Joint Surg Am 1976;58:
spent $1074-82$.
107.

3 Danto MI, Woo SL-Y. The mechanical properties of patellar tendon over a range of strain rates. J Orthop Res 1993;1:58-67.
Anderson-MacKenzie JM, Billingham ME, Bailey AJ. Collagen remodeling in the anterior cruciate ligamen associated with developing spontaneous murine osteoar-
thritis. Biochem Biophys Res Commun 1999;258:763-7. 